\title{
Estimativa do fluxo de material em suspensão do Rio Paraíba do Meio (AL).
}

\author{
Estimate of the flow of material in suspension of Paraíba do Meio (AL) \\ GOMES ${ }^{1}$, A. A. S.; MEDEIROS ${ }^{2}$, P. R. P.; LIMA³ $^{3}$ A. C. C. \\ adsson1992@gmail.com
}

\section{Resumo}

O Rio Paraíba do Meio é considerado um rio de pequeno porte e não possui estudos referentes ao transporte de material em suspensão cujo ele é capaz de transportar, e vem sofrendo com interferências antrópicas ao longo de sua margem, mudando as condições físicas e biológicas do ambiente no qual o rio pertence e por consequência causando alterações. As coletas foram realizadas entre agosto de 2015 e junho de 2016, nas atividades de campo foram realizadas coletas mensais de amostras de água com auxílio de garrafa de coleta tipo Van Dorn e medição de parâmetros ambientais. Os locais de coletas foram georreferenciados com GPS Garmin e-trex. Nas atividades de laboratório foram aplicadas técnicas de análise para determinação de material em suspensão, segundo Strickland \& Parsons (1972). Os cálculos de carga seguiram metodologia de Medeiros (2007). Mesmo os rios considerados de pequeno porte possuem uma grande importância no transporte de material em suspensão e nutrientes para a interface continente oceano. A carga de material em suspensão mostrou ser controlada de acordo com os regimes climáticos, geológicos e morfológicos.

Palavras-chave: Rio paraíba, fluxo de nutrientes, fluxo de material em suspensão.

\begin{abstract}
The Paraíba do Meio is considered a small river and has no studies regarding the transport of suspended material which he is able to carry, and has been suffering withantropic interferences along its edge, changing the physical and biological conditions of the environment in which the river belong and consequently causing changes. The collections were made between August and June 2016, 2015 in field activities were conducted monthly samplings of water samples with the help of bottle type VanDorn collection and measurement of environmental parameters. The collections were georeferenced locations with GPS Garmin e-trex. Laboratory activities were applied analytical techniques for determination of material in suspension, according to Strickland \& Parsons (1972). The load calculations followed methodology of Mann (2007). Even the rivers considered small businesses have a great importance in the transport of suspended material and nutrients to the ocean continent interface. The suspended material load proved to be controlled according to the climatic, geologicaland morphological regimes.
\end{abstract}

Keywords: Paraíba ryver, nutrient flow, flow of material insuspension. 


\section{INTRODUÇÃO}

O Rio Paraíba do Meio está situado entre os estados de Alagoas e Pernambuco, nasce no município de Bom conselho-PE e deságua no Laguna Manguaba, no município de Pilar-AL. A bacia do Rio Paraíba possui uma área total de $3.127,83 \mathrm{~km}^{2}, 37,6 \%$ da bacia correspondente a 1.175,33 $\mathrm{km}^{2}$ localizam-se no estado de Pernambuco, e a maior parte da bacia se encontra no território alagoano com uma área correspondente a 1.952,5 $\mathrm{km}^{2}$ (62\% do total) (PDRH, 2001).

O Rio Paraíba do Meio é considerado um rio de pequeno porte não possui estudos referentes ao transporte de material em suspensão cujo ele é capaz de transportar, além disso vem sofrendo com interferências antrópicas ao longo de sua margem, mudando as condições físicas e biológicas do ambiente no qual o rio pertence e por consequência causando alterações no próprio rio.

Devido aos usos múltiplos desse ambiente no qual apresenta importância do ponto de vista ecológico e comercial, esse trabalho pretende realizar estudo sobre a carga de material em suspensão e nutrientes do rio Paraíba durante o ano hidrológico de 2015-2016.

\section{METODOLOGIA}

O Rio Paraíba do Meio localiza-se entre os paralelos $08^{\circ} 44^{\prime}$ e $09^{\circ} 39^{\prime}$ latitude sul e meridianos $35^{\circ} 45^{\prime}$ e $36^{\circ} 45^{\prime}$ longitude oeste (Figura 1), ao longo dos seus 171,98 km apresenta 126,57 km de extensão que percorre áreas do estado de Alagoas com regime fluvial perene, e 45,41 km no estado de Pernambuco com um regime fluvial intermitente. $\mathrm{Na}$ tabela 1 são apresentadas características físicas da Bacia do Rio Paraíba evidenciando as informações já apresentadas.

Tabela 1: Características Físicas da Bacia Rio Paraíba do Meio

\begin{tabular}{|c|c|c|c|}
\hline \multicolumn{4}{|c|}{ Características Físicas da Bacia Rio Paraíba do Meio } \\
\hline Área Total & $3.127,83 \mathrm{~km}^{2}$ & $\begin{array}{c}\text { Coeficiente de } \\
\text { Compacidade Kc }\end{array}$ & 2.30 \\
\hline Perímetro Total & $459,60 \mathrm{~km}$ & Fator de Forma Kf & 0,106 \\
\hline Área em Alagoas & $1952,5 \mathrm{~km}^{2}$ & $\begin{array}{c}\text { Densidade de Drenagem } \\
\text { Dd }\end{array}$ & $\begin{array}{c}0,63 \mathrm{~km} / \\
\mathrm{km}^{2}\end{array}$ \\
\hline
\end{tabular}




\begin{tabular}{|c|c|c|c|}
\hline $\begin{array}{c}\text { Área em } \\
\text { Pernambuco }\end{array}$ & $1175,33 \mathrm{~km}^{2}$ & Densidade dos Rios Dr & $\begin{array}{c}0,437 \mathrm{~km} / \\
\mathrm{km}^{2}\end{array}$ \\
\hline Extensão Total & $171,98 \mathrm{~km}$ & $\begin{array}{c}\text { Extensão Média de } \\
\text { Escoamento Superficial E }\end{array}$ & $0,397 \mathrm{~km}$ \\
\hline $\begin{array}{c}\text { Extensão Total de } \\
\text { todos os Rios }\end{array}$ & $1983,95 \mathrm{~km}$ & Razão de Bifurcação Rb & 4 \\
\hline Ordem da bacia & $5^{\circ}$ ordem & $\begin{array}{c}\text { Declividade Media da } \\
\text { Bacia Imed }\end{array}$ & $\begin{array}{c}16,77 \mathrm{~m} / \mathrm{km} \\
=1,67 \%\end{array}$ \\
\hline
\end{tabular}

Fonte: PDRH (2001)

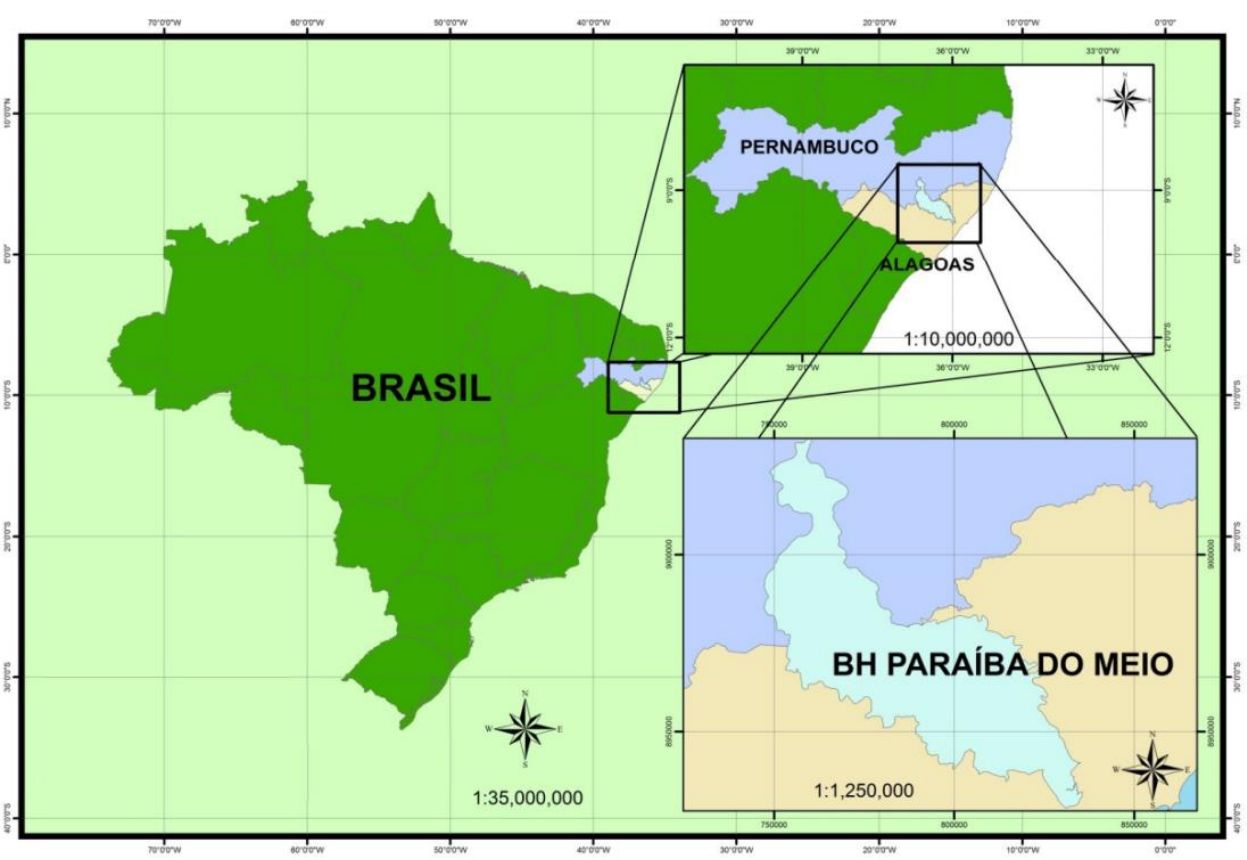

Figura 1: Área de estudo, bacia do Rio Paraíba do Meio. Fonte: Rodrigues (2012).

Segundo a classificação de Köppen, parte da bacia do Rio Paraíba no estado de Alagoas se caracteriza como clima tropical quente e chuvoso com verão seco do tipo As' (Figura 2), apresentando estações bem definidos de novembro a março (seca) e de abril a julho (chuvosa). A pluviosidade média anual na bacia é $1.400 \mathrm{~mm}$ (SUDENE, 1999).

Segundo PDRH (2001) a distribuição da precipitação pluviométrica na área da bacia está concentrada no período de abril a agosto (Figura 3), onde neste intervalo se concentra 69,8\% da precipitação anual, os demais meses (janeiro a março e setembro a dezembro) corresponde a $30,2 \%$, aspectos típicos da região nordeste do Brasil. É 
notório a maior contribuição das condições pluviométricas do estado de Alagoas na bacia do Rio Paraíba durante todo o ano hidrológico.

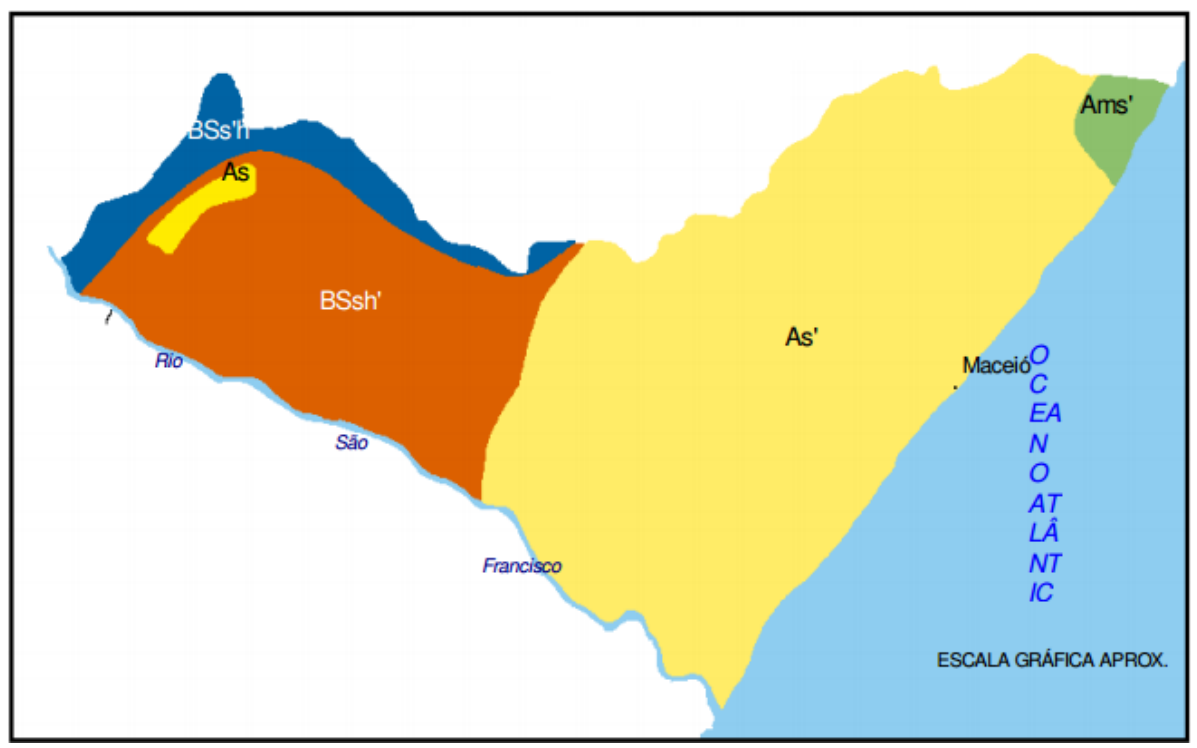

Figura 2: Classificação climática de acordo com Köppen para o Estado de Alagoas. Fonte: PDRH (2001).

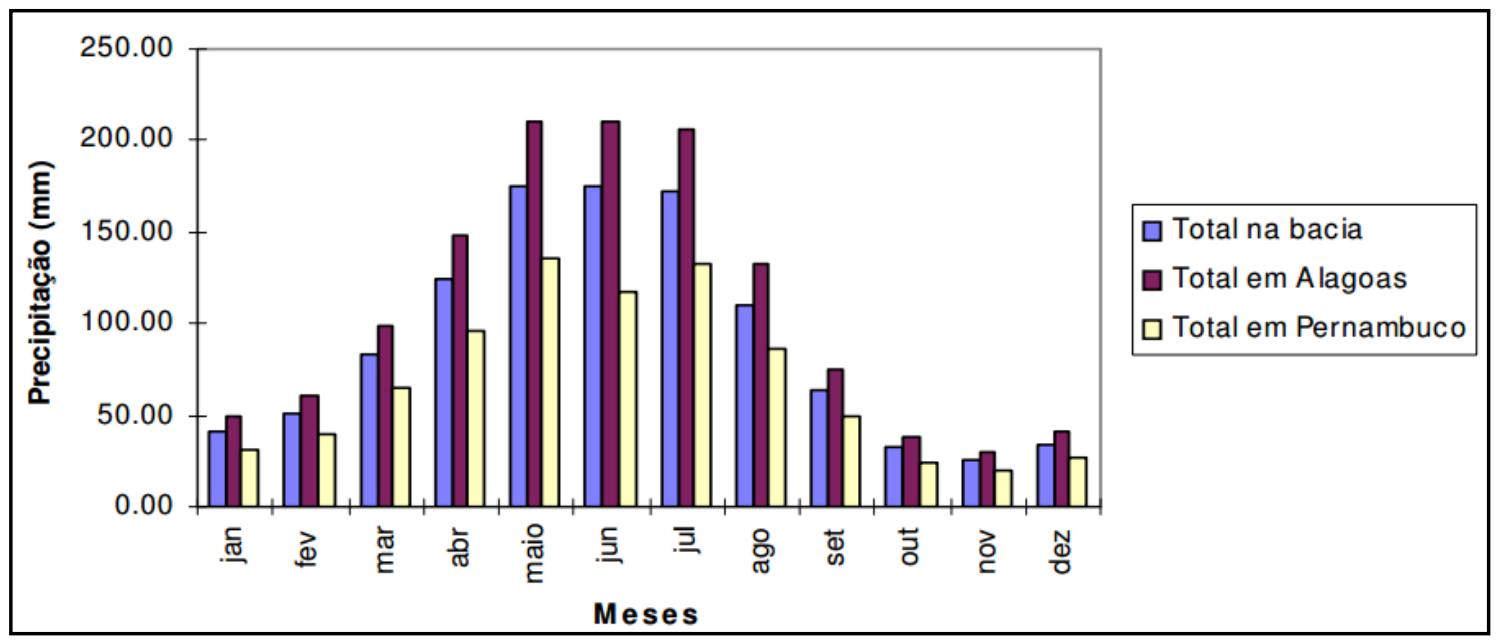

Figura 3: Precipitações Médias Mensais da Bacia do Rio Paraíba do Meio e as Contribuições de Pernambuco e Alagoas. Fonte: PDRH (2001).

Foram realizadas coletas mensais de amostras de água com auxílio de garrafa de coleta tipo Van Dorn e medições de parâmetros ambientais. Os locais de coletas foram georreferenciados com GPS Garmin e-trex. Nas atividades de laboratório foram aplicadas técnicas de análise para determinação de material em suspensão, segundo Strickland \& Parsons (1972). Os cálculos de carga seguiram metodologia de Medeiros (2007). 


\section{RESULTADOS E DISCUSSÃO}

Em razão de todos os dados de vazão dos anos de 2015 e 2016 não estarem disponíveis, os fluxos mensais de material em suspensão foram calculados utilizando-se as médias mensais históricas (www.ana.gov.br) dos últimos trinta anos.

De acordo com as amostragens no rio Paraíba, entre os meses de agosto/2015 e junho/2016, os meses de abril/16 (47,33 mg/L), maio/16 (49 mg/L) e junho/16 (53,12 $\mathrm{mg} / \mathrm{L}$ ) apresentaram as maiores médias mensais de concentração de material em suspensão. O mês de fevereiro/16 apresentou a menor média mensal de concentração de material em suspensão, 9,33 mg/L como descreve o gráfico 1 .

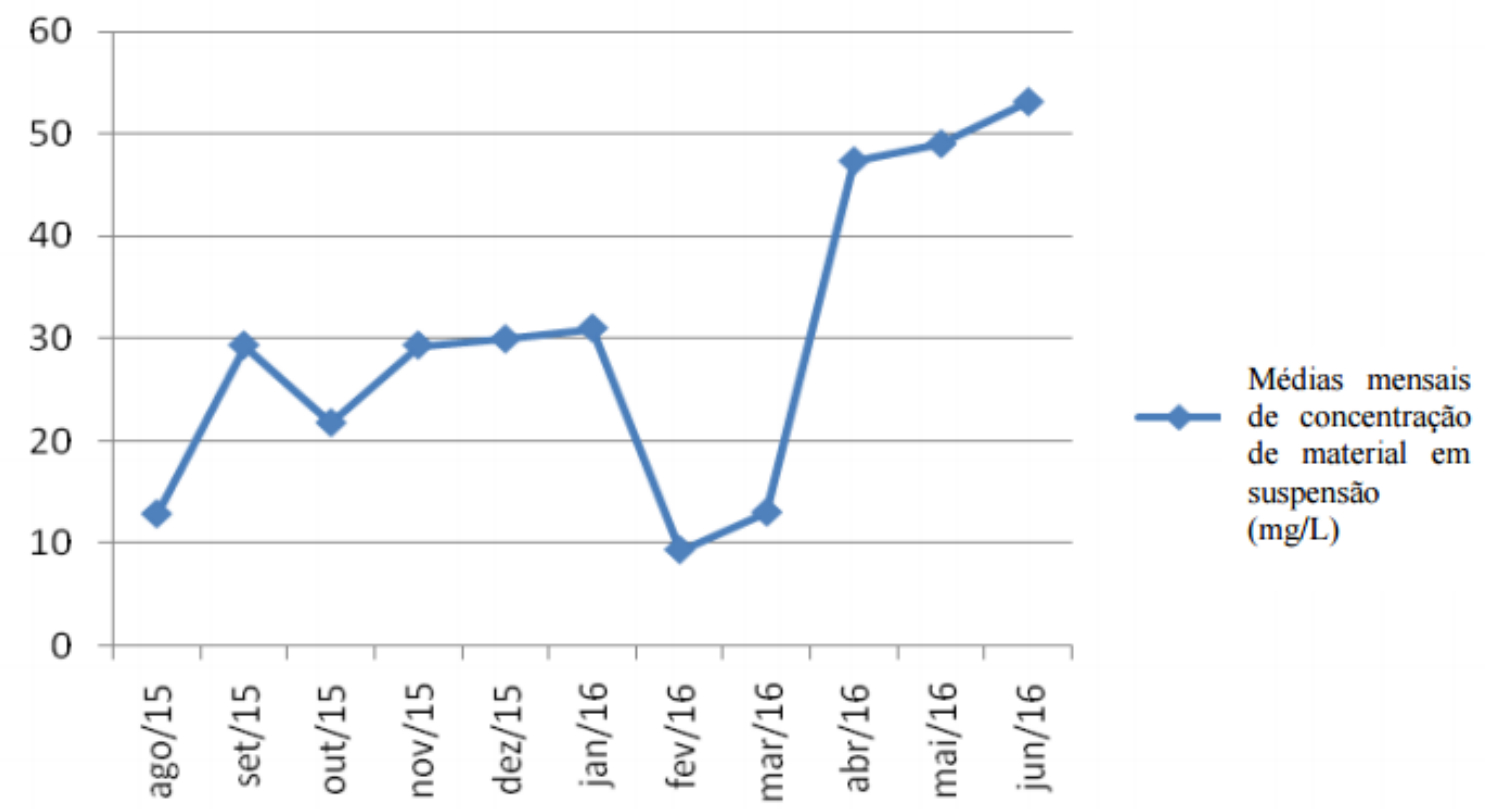

Gráfico 1: Gráfico das médias mensais de concentração de material em suspensão no ponto de coleta no Rio Paraíba. Fonte: Autor, 2016

Os maiores valores mensais de vazão do rio Paraíba ocorreram nos meses de agosto/15, mai/16 e junho/16, com os valores $36,66 \mathrm{~m}^{3} / \mathrm{s}, 29,48 \mathrm{~m}^{3} / \mathrm{s}$ e $42,88 \mathrm{~m}^{3} / \mathrm{s}$ (gráfico 2) respectivamente, esses meses fazem parte do período chuvoso característico da região, consequentemente eles tiveram as maiores cargas mensais de material em suspensão, 1.260.054,16 t, 3.869.002,37 t e 5.904.020,28 t respectivamente. Os meses de dezembro/15, janeiro/16 e fevereiro/16 apresentaram as menores cargas mensais de 
sedimentos, 493.688,99 t, 664.838,87 t e 250.139,34 t respectivamente, sendo esse o período seco característico da região como visto anteriormente.

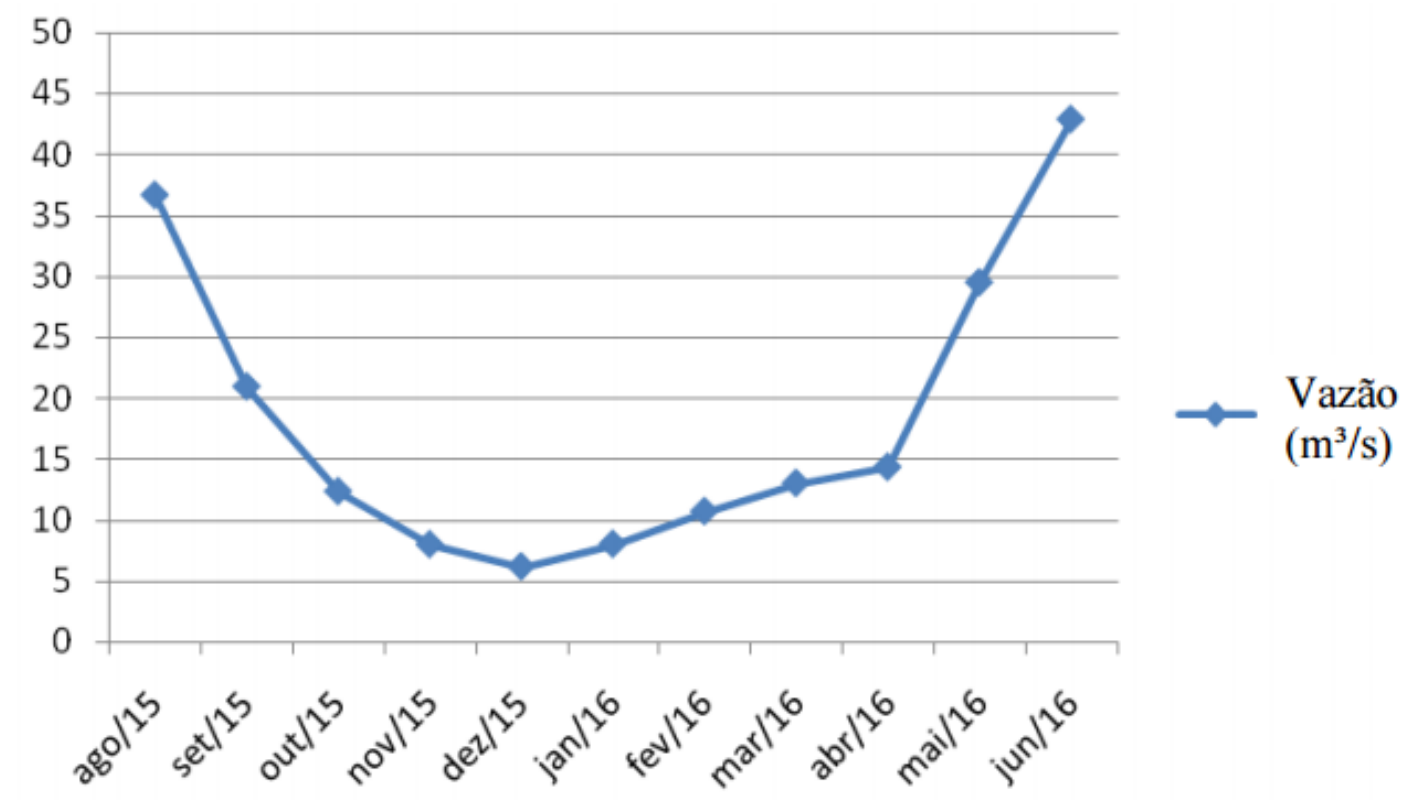

Gráfico 2: Gráfico das vazões médias do ponto de coleta no Rio Paraíba. Fonte: Autor, 2016.

As menores vazões do rio Paraíba ocorreram nos meses de novembro/15 (7, 98 $\left.\mathrm{m}^{3} / \mathrm{s}\right)$, dezembro/15 $\left(6,16 \mathrm{~m}^{3} / \mathrm{s}\right)$ e janeiro/16 $(8 \mathrm{~m} / \mathrm{s})$, atribuindo relação direta com $o$ período seco da região, que mesmo estando entre os maiores valores de concentração de material em suspensão estavam entre os menores aportes mensais de material em suspensão, mostrando a relação entre a vazão e o fluxo de material em suspensão.

De acordo com Gama (2006) o Rio Paraíba do Meio vem sofrendo com a ocupação desordenada em seu leito e ao longo de toda sua bacia, ocorrendo o lançamento de efluentes domésticos e o descarte inapropriado de resíduos. Nos meses onde a média de concentração foi alta, mas a carga de material transportado foi baixa havia um volume de água mais baixo que a média correndo pelo rio. Dessa forma a baixa carga de material transportado pode ser reflexo da baixa capacidade de erosão do rio nessa época do ano, pois em condições naturais, as concentrações e os fluxos de material em suspensão de rios possuem estreita relação com vazão (Restrepo e Kjerfve 2001. Citado por Medeiros 2015).

Pode ser destacada a alta concentração de material em suspensão, mesmo com a vazão e consequentemente a capacidade de erosão baixa, pode ser reflexo dos efluentes jogados ao longo do leito do rio (GAMA, 2006). As relações de parâmetros 
morfológicos e da vazão sobre a produção de sedimentos em suspensão são consideravelmente alteradas em função dos múltiplos impactos antrópicos sobre as bacias de drenagem (Souza \& Knoppers 2003. Citado por Medeiros 2015). As cargas mensais de material em suspensão podem ser observadas no gráfico 3.

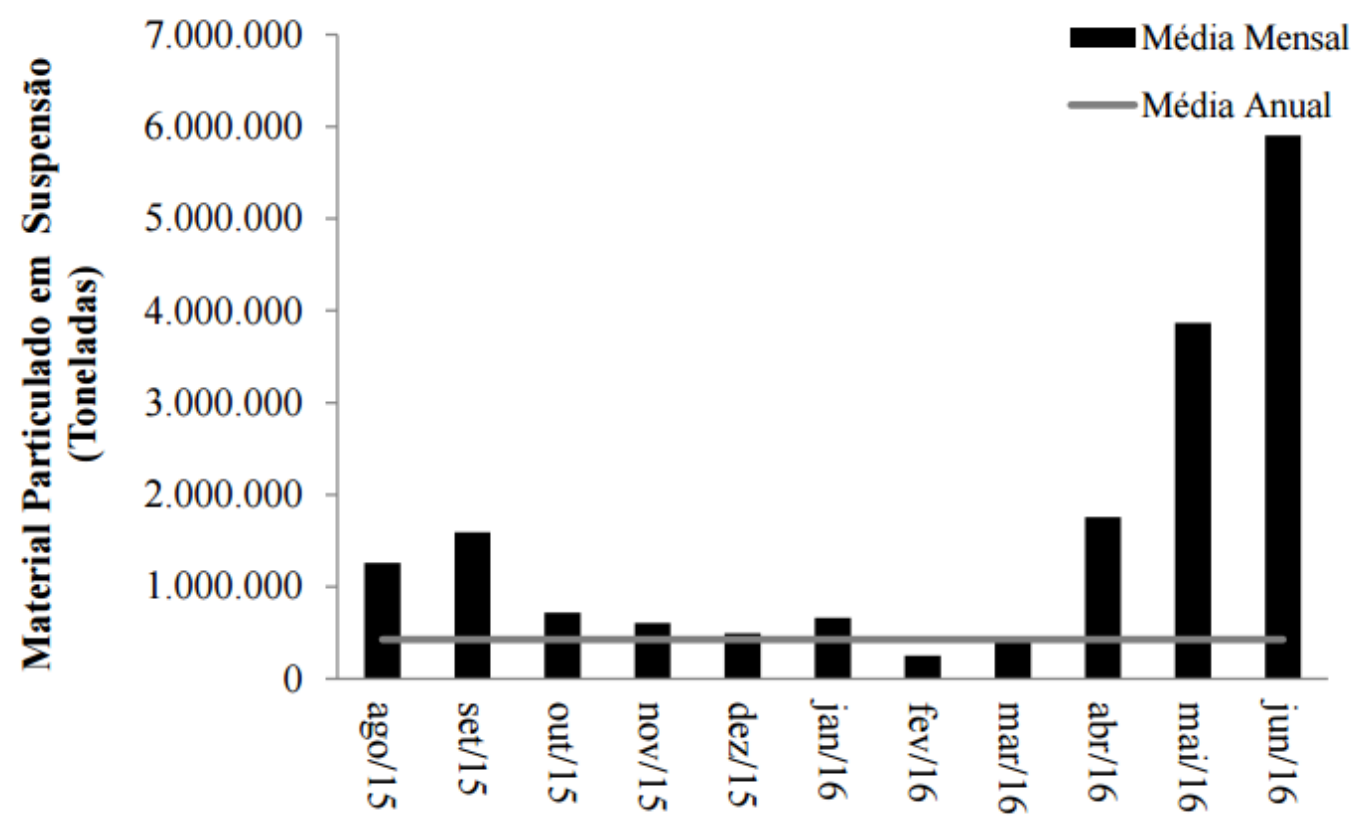

Gráfico 3: Gráfico da carga mensal de material em suspensão do Rio Paraíba. Fonte: Autor, 2016.

\section{CONSIDERAÇÕES FINAIS}

A carga de material em suspensão mostrou ser controlada de acordo com os regimes climáticos, e características geológicos e morfológicos. Em meses da estação seca as vazões foram baixas e por isso ocorre a concentração maior de materiais em suspensão e nos meses de vazões altas ocorreram uma grande concentração de material em suspensão, devido a maior capacidade de erosão dos rios e dos sedimentos carregados das encostas pela chuva, e grandes cargas de materiais.

\section{REFERÊNCIAS}

GAMA, W. M.. Impactos das mudanças climáticas na resposta hidrológica da bacia hidrológica da bacia hidrográfica da bacia do Rio Paraíba do Meio (AL/PE). Dissertação de Mestrado apresentada ao Programa de Pós-Graduação em Saneamento e Recursos Hídricos da Universidade Federal de Alagoas, 2011. 114 p. 
GAMA, N. A. et al. Aspectos geoambientais das áreas urbanas dos municípios ao longo do rio paraíba. In: REUNIÃO ANUAL DA SBPC, 58., 2006, Florianópolis. Anais eletrônicos... São Paulo: SBPC/UFSC, 2006. Disponível em: http://www.sbpcnet.org.br/livro/58ra.

MEDEIROS, P. R. P. et al. Comportamento da turbidez e material em suspensão, em um rio com vazão regularizada por sistema de barragens em cascata (NE, Brasil). Geochimica Brasiliensis, Ano 29, n. 1. São Paulo: 2015.

PLANO DIRETOR DA REGIÃO HIDROGRÁFICA DO RIO PARAIBA DO MEIO PDRH. v. 1, cap 1 p. 18 - 23. 2001.

RODRIGUES, M. T. Acoplamento do modelo hidrologico MGB ao modelo atmosferico WRF visando estimar vazão na bacia do rio Paraiba do meio - AL/PE. Dissertação de Mestrado em Meteorologia apresentada ao Instituto de Ciências Atmosféricas, Universidade Federal de Alagoas. 2012. $101 \mathrm{f}$.

SOUZA, W. F. L. et al. Impactos de barragens sobre o fluxo de materiais na interface continente-oceano. Revista virtual de química, Ano 03, n. 2. Rio de Janeiro: 2011.

SOUZA, W. F. L. et al. Geoquímica e fluxos de nutrientes, ferro e maganês para a costa leste do Brasil. Geochimica Brasilienses, Ano 17, n. 2. São Paulo: 2003.

SUDENE. Plano Diretor de Recursos Hidricos da Bacia do Rio Mundaú. Recife-PE, 1999.

\section{AGRADECIMENTOS}

Meu professor Paulo Ricardo Petter Medeiros, pois, sem sua orientação esse trabalho não seria possível, aos técnicos do laboratório (LABMAR), por suas contribuições indispensáveis.

Recebido em: 14/08/2016

Aceito para publicação em: 01/10/2016 